\title{
Construction of High Quality Course for Graduate Students in Engineering Majors Based on Ability Training
}

\author{
Fuquan Pan*, Lixia Zhang, Changhe Li, Min Li, Jinshun Yang, Chenxiu Feng, Xinyu \\ Qi, Jinli Wei
}

School of Mechanical and Automotive Engineering, Qingdao University of Technology, Qingdao, Shandong, 266520, China

*Corresponding author

\begin{abstract}
In higher education, engineering majors play an important role in all disciplines, and the number of engineering majors also accounts for the highest proportion. In the talent training system, graduate student belongs to a higher position. It is an important way to cultivate high quality and high ability graduate students through the construction of high quality courses. Through the investigation, the quality and ability of graduate students in engineering majors are obtained. Focusing on the quality and ability cultivation of graduate students, the study discussed the goal orientation of high quality courses, the design of knowledge content, explanation content, course assignment, and expounded the teaching methods of high quality courses. The study results can provide reference for the construction of high quality courses for graduate students in engineering majors.
\end{abstract}

Keywords: Ability training, Engineering major, Graduate student, High quality course

\section{INTRODUCTION}

The engineering major refers to the major of engineering. Engineering discipline refers to the study and application of technology, such as machinery, automobile, construction, civil engineering, water conservancy, environment, transportation, logistics, automation, communication, etc. Engineering discipline is a discipline developed by applying the principles of basic sciences such as mathematics, physics and chemistry and combining the technical experience accumulated in production practice. The training objective of engineering majors is to train senior engineering and technical talents who are engaged in planning, exploration, design, manufacturing, construction, construction, transportation and other aspects in corresponding engineering fields.

In the higher education system, there are four levels: junior college student, undergraduate, graduate student and doctoral student. Graduate students belong to a higher position in the talent training system. In recent years, with the development of science and technology, as well as the needs of building a modern society, many countries are training a large number of graduate students to meet the needs of society. Take China as an example. In the past 40 years, the number of graduate students has increased significantly, and the total number of degree awards from 1981 to 2018 exceeded 8 million. The number of graduate students enrolled since 2000 is shown in Figure 1.

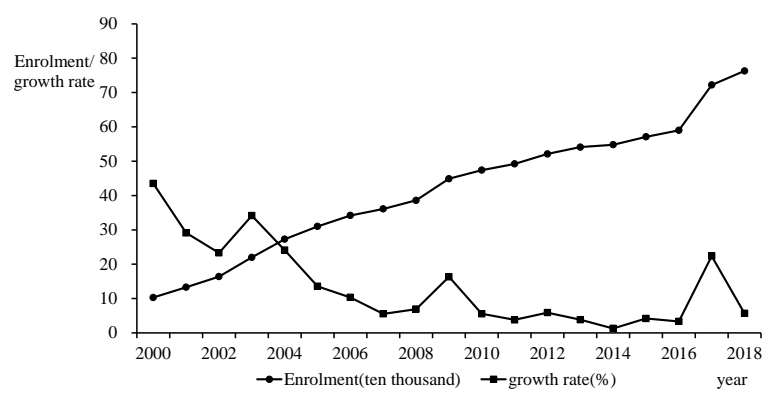

Figure 1 Number of postgraduate enrollments in China

As shown in Figure 1, in China, the enrollment scale of graduate students is increasing rapidly. In fact, in most countries, especially in developed countries, the number of graduate students is also increasing. In the face of a large number of graduate students, how to improve the effect of curriculum teaching and the quality of postgraduate training are an important issue for universities, and also the basis for promoting the development of science and technology.

\section{THE QUALITY AND ABILITY OF POSTGRADUATE IN ENGINEERING MAJORS}

Graduate students in engineering majors are different from undergraduates in engineering majors. The society has high expectations for the quality and ability of the graduate students. By investigating a large number of engineering 
enterprises, this study has learned that the quality requirements of enterprises for engineering graduate students include professional quality, moral quality and psychological quality.

(1) Professional quality is mainly reflected in: 1) Graduate student should master the basic theory of their major well.

2) Graduate student has a wide range of knowledge, and can flexibly use knowledge to solve complex engineering problems. 3) Graduate student has innovative consciousness and ability. 4) Graduate student has the ability of scientific research, international academic exchange and good communication skills.

(2) Moral quality is mainly reflected in: Graduate student should abide by discipline and law, be honest, be willing to help others, has sense of responsibility, sense of unity and cooperation, etc.

(3) Psychological quality is mainly reflected in: Graduate student should have good mentality, interpersonal relationship of competition and cooperation, ability to bear setbacks, emotional adjustment, and environment adaptation, etc.

It can be seen that a university needs to pay a lot to train a graduate student with high quality and ability in engineering majors. Among these qualities and abilities, professional quality and ability are the primary objectives of university training. Of course, moral quality and psychological quality are also training objectives $[1,2]$.

\section{CONSTRUCTION OF HIGH QUALITY COURSE}

Generally speaking, graduate students in engineering majors have special training programs. The purpose of the training program is to ensure the quality and ability of postgraduate students. The curriculum system is an important part of the training program. The curriculum system is the direct guarantee measure to cultivate the professional quality and ability of the graduate students, and the high quality course in the curriculum system plays a great role in the cultivation and improvement of the quality and ability of the graduate students. Therefore, every university attaches great importance to the construction of high quality course [3].

\subsection{Objectives and Functions of High Quality Course}

Broadly speaking, high quality courses are required or core courses. Therefore, high quality courses should highlight the quality and ability training objectives for graduate students, especially for graduate students in engineering majors. For a specific course, the Objectives are reflected in graduate students' mastery of the basic knowledge of the course, the ability to apply knowledge to specific engineering projects, the ability to engage in some work, and the cultivation of related concepts.
Taking the high quality course "traffic safety theory and technology" in the transportation engineering major as an example, the subjects of the course are to enable graduate students to establish a "people-oriented" awareness of traffic safety, master the basic principles of traffic safety, such as reliability theory, accident cause theory, accident prevention theory, etc., and deeply understand the traffic behavior of drivers and other traffic participants, and master the influence mechanism of the traffic facilities such as traffic lights, traffic monitoring, etc. on human and traffic safety, and master the evaluation method and technology of traffic safety at road intersections, the statistical analysis of traffic accidents and the technology of accident recurrence, etc. The subjects enable students to have the ability to engage in traffic safety research and teaching in the field of traffic safety.

The function of high quality course is mainly reflected in the function of the course in the whole course system, whether it is a link between the preceding course and the following course. For example, in a certain major, it should be clear whether this high quality course is a basic course, whether it is a pre course of some courses, and what the subsequent courses are.

\subsection{Design of High Quality Course}

Teachers in charge of high quality course should design high quality courses reasonably on the basis of fully analyzing the objectives and functions of high quality courses.

1. Knowledge composition and ability composition of course. The teachers in charge of the course should systematically analyze the knowledge content of the course, analyze the knowledge classification of the course from the perspective of structure, and the knowledge classification should correspond to the ability cultivation of graduate students.

Taking the high quality course "traffic safety theory and technology" as an example, the knowledge composition of this course is divided into three parts: (1) traffic safety theoretical knowledge, (2) traffic safety method knowledge, and (3) traffic safety technical knowledge. These three parts of knowledge correspond to the three abilities of graduate students (1) theoretical ability, (2) innovation ability, and (3) practical ability. The ability of graduate students can be improved by the knowledge, and the knowledge of graduate students can be supplemented by the ability.

2. The proportion of explanation content and self-study content. Postgraduate students are different from undergraduate students, and the proportion of self-study content of graduate students is relatively larger. However, generally speaking, high quality courses are very important courses. The content of the courses is relatively profound, and the knowledge content is also very important, so the explanation of teacher is also indispensable. In all aspects, the proportion of explanation content of high quality courses and self-study content of graduate students is about 
2:1. In addition, the learning efficiency of the self-study content of the graduate students should also be guaranteed $[4,5]$.

3. Selection of textbook and references. Teaching textbook is the carrier of course knowledge, so high quality textbooks can lay the foundation for the good teaching effect of the course. Therefore, the teachers in charge of the course should be clear about the existing textbooks and choose 1-2 suitable textbooks to recommend to the graduate students. Of course, if possible, teachers in charge of high quality courses can write textbooks according to their own needs, which are more targeted. In order to expand the knowledge of graduate students, the number of references is more than that of textbooks. References can be either scientific papers or scientific reports, not limited to domestic ones, and foreign research papers are also worth recommending for graduate students to read.

4. Preparation or selection of cases. For graduate students in engineering majors, they should not only master the theoretical knowledge involved in the course, but also learn to integrate theory with practice. Therefore, the case is an important way to explain from theory to practice. The teacher in charge of the course should plan cases from the perspective of the whole course. It's better to have cases in each chapter. The important chapters need express the knowledge that students should master through several cases. Case construction is a characteristic part of high quality curriculum, which is not covered in this study due to limited space. Please refer to the relevant literature [6,7 ].

5. Design and arrangement of course assignments. Graduate student is a higher level of education. Therefore, the teachers in charge of high quality courses need talents to plan course assignments. Combined with theoretical knowledge and practical problems to be solved, the teachers in charge of the course plan several different course assignments in the form of similar research paper requirements. Graduate students are free to choose different course assignments, and they can even draw up their own thesis topics if they have special ideas.

\section{TEACHING METHODS OF HIGH QUALITY COURSE}

With the development of the times, modern teaching methods have gradually become more and more. For high quality courses, the use of scientific and reasonable teaching methods is an important way to ensure the professional quality and ability of graduate students.

\subsection{Teaching Methods}

In the process of teaching, the teachers in charge of high quality courses should always implement the concept of "student-oriented", and adopt targeted multimedia classroom teaching, experimental teaching, practice teaching and other teaching methods according to teaching objectives, teaching contents of different links and teaching requirements.

In the process of theory teaching, teachers use various teaching methods and means such as multimedia teaching, heuristic teaching and case analysis teaching to activate the classroom atmosphere, stimulate students' interest in learning, deepen students' understanding of theoretical knowledge, and improve the effect of classroom teaching. In the aspect of experimental teaching, on the one hand, teachers should strengthen the teaching guidance and assessment in the process of experimental teaching, increase the participation of graduate students in the experiment by themselves, and improve the graduate students' attention to the curriculum experiment. On the other hand, teachers open the laboratory after class course, allowing graduate students to study independently in the laboratory in their spare time, which can promote the practical ability of graduate students.

In practice, the University and the teachers in charge of high quality courses should strengthen cooperation with enterprises and establish practice bases [8]. In their spare time, graduate students go to enterprises to practice in specific engineering work, so as to exercise their practical ability. Taking the high quality course "traffic safety theory and technology" as an example, in cooperation with the design institute, traffic bureau and traffic police team, the part-time teachers of the cooperation enterprises, combining with the actual traffic accident cases, explain the process of road traffic accident treatment, traffic accident reconstruction analysis, etc. In addition, graduate students can get close contact with traffic violation capture equipment and system, learn its principle and use method, and increase the chance of practical exercise. This better realizes the combination of theory and practice, so that students can not only deepen their understanding of the course content in the process of practice, but also get the opportunity to solve practical problems with the knowledge they have learned. This not only improves the practical ability of graduate students, but also deepens their understanding of the importance of learning the course, and promotes the realization of the teaching objectives of this course.

\subsection{Application of Information Teaching Means}

In the process of teaching, teachers in charge of high quality course should make full use of modern information teaching technology. Of course, the traditional excellent teaching methods cannot be abandoned. A good method worth advocating is the close combination of traditional excellent teaching method, modern multimedia technology and network teaching method to form a trinity comprehensive teaching method, which can give full play to the advantages of various teaching methods, improve teaching effect, improve teaching level and stimulate students' interest in learning. 
Teachers in charge of quality courses should make animations, pictures and videos to enrich multimedia teaching materials. These teaching materials are clear, intuitive and vivid, which makes it easier for graduate students to master knowledge and achieve good teaching results.

High quality course needs to establish a course website with the function of online teaching, so that students who do not have time to take classes in class can learn by themselves, or students can learn repeatedly through the course website, forming the mutual supplement of offline teaching and online teaching. High quality course needs to establish rich network teaching resources, such as syllabus, teaching calendar, electronic teaching plan, electronic courseware, electronic teaching materials, teaching video, problems to be solved, course papers to be arranged, etc. These teaching resources can be freely browsed and downloaded. In addition, students can also interact online with the teacher in charge of the course on the course website.

\subsection{Innovation and Exploration of Teaching Methods}

The construction of high quality course is not uniform. Teachers in charge of high quality courses should innovate and explore teaching methods that reflect the characteristics of courses and teaching styles, so that the courses have their own characteristics. Taking the high quality course "traffic safety theory and technology" as an example, the biggest feature of this course is the integration of knowledge and life. Because the knowledge learned by graduate students in this course can not only be used in scientific research, be used to solve the traffic safety problems encountered in practical work, but also can be used by graduate students to protect their own traffic safety in the whole life.

\section{CONCLUSION}

Based on the increasing number of postgraduate enrollment year by year, this study obtained the quality and ability of graduate students in engineering majors through investigation. Focusing on the ability cultivation of graduate students, this study discussed the subject orientation of high quality course, the design of knowledge content, explanation content and course assignment, and teaching methods of high quality course. This provides a reference for promoting the construction of high quality courses for graduate students in engineering majors.

\section{ACKNOWLEDGEMENT}

This research was financially supported by the High Quality Course Construction Project of Shandong Province Postgraduate Education (SDYKC17044), the Cooperative Education
Project of Chinese Ministry of Education (201702117008), and the Teaching Quality Improvement Project of Qingdao University of Technology (F2017-069-5, F2017-114, F2017-069).

\section{REFERENCES}

[1] F.Q. Pan, L.X. Zhang, F.Y. Wang, J.Z. Wang, N.X. Song, Practice teaching reform of vehicle engineering specialty for social needs, Proceedings of 2010 International Conference on Education and Sports Education, 1(2010) 188-191.

[2] F.Q. Pan, L.X. Zhang, F.Y. Wang, Y. Yan, N.X. Song. Society Need-oriented Feature Construction of Traffic Engineering Major, Proceedings of 2011 International Conference on Information Science and Education Technology, 2(2011) 493-497.

[3] F.Q. Pan, F.Y. Wang, L.X. Zhang, X.F. Chen, M. Li, R.C Liu, Construction of excellent courses of traffic safety engineering, University Education, (2013) 64-65.

[4] M. Li, F.Q. Pan, X.F. Chen, G.X. Kang, F.W. L.X, Zhang, Research on teaching reform of transportation technology economics based on OBE, Education modernization, 11 (2019) 69-71.

[5] M. Li, W.W. Qi, F.Q. Pan. Research on improving the efficiency of university classroom, Journal of Science of Teachers' College and University, 05(2013) 28.

[6] L.X. Zhang, F.Q. Pan, N.X. Song, Application of case teaching method in the course of vehicle engineering introduction, Education Teaching Forum, 48 (2016) 180-181.

[7] L. Zheng, L.Q Jin, X.M Yu, Guided by the concept of new engineering, build the teaching cases in the field of vehicle engineering, Education Teaching Forum, 43 (2018) 114-116.

[8] F.Y. Wang, F.Q. Pan, X.S. Zou, J.Y. Ji, G.Q Ji, M.J. Zhang. Research on the training mode of postgraduate based on the mechanism of school enterprise collaborative innovation, Education Teaching Forum, 10 (2018) 109-111. 